\title{
Tumor of the Thecoma/Fibroma Group
}

National Cancer Institute

\section{Source}

National Cancer Institute. Tumor of the Thecoma/Fibroma Group. NCI Thesaurus. Code C39950.

A sex cord-stromal tumor that arises from the ovary or the testis. Representative examples include fibroma, fibrosarcoma, and thecoma. 